Sorin Adam Matei (Purdue University, USA) Lorenza Parisi (Link Campus University, Italy), Francesca Comunello (Lumsa University, Italy), Kelly Vibber (University of Dayton, USA)

\title{
ALTERPODES: COMMUNICATION BIASES IN PLAUSIBLE REASONING ABOUT GEOGRAPHIC PERCEPTION OF PLACE AND SPACE
}

\begin{abstract}
${ }^{1}$
This study builds on existing work on cartographic thinking in everyday life to better understand how digital and/or traditional media influence our perceptions of continental scale geography. Using a mixed, US-Italian sample of college students living in cities on similar latitudes, we found that there is a bias in placing U.S. cities further north and European cities further south than where they should be. Such biases reflect a process of 'plausible reasoning,' which assumes that places are located cartographically in a biased way due to cultural-cognitive processes facilitated by media. The specific media found to be related with such biases in this study and directions for future research are discussed.
\end{abstract}

This study examines how "plausible reasoning" facilitated by media connections contributes to geographic misperceptions. We explore the possibility that people infer geographic alignment of global cities especially on latitude from perception of cultural similarities between the people who inhabit them. A core question it investigates, building on existing literature on cartographic reasoning and knowledge (Friedman and Brown, 2000a, 200b), is that cultural and social heuristics may be shaped by social learning and interaction channels, such as those mediated by social media and by knowledge/media resources more broadly. It is our contention that in addition to basic categorical judgment mistakes, induced by basic mapping information errors, we can also detect some errors and corrections induced by social and mediated experiences. From a broader perspective, our study aims to address the question if easier access to media, especially more sophisticate channels and source of digital information (social media, maps, social networking) alleviates or not geographic misperceptions. In a word, does access to social media make us sense of geographic better and how does such access interact with our cultural biases?

\section{LITERATURE REVIEW}

The starting point of our investigation is a more fundamental question: what factors shape the way in which we store and retrieve geographic information, especially at the global level? Cartographers who study the way in which people perceive and 
store information about physical space have determined that global/continental space is perceived and stored not as a continuum entity, but as a conglomeration of discrete regions or places, which are organized hierarchically, according to a model of 'plausible reasoning.' Friedman and Brown note, 'although people may generally have inexact item-level knowledge (e.g. they do not know the specific latitudes of most cities), they have a wealth of other specific and general beliefs-correct or incorrect-about the cities and the geographic regions and continents to which the cities belong' (2009: 94). Such beliefs typically pair places on the basis of climate or political/cultural affiliation by a process of plausible reasoning (Collins and Michaelski, 1989; Friedman and Brown, 2000a, 2000b). Such processes typically infer item (city-level) places from regional (country or continent-level) affiliation (Friedman and Brown, 2000a, 2000b). For example, southern cities in the United States are seen as being at the same level as Southern (Mediterranean) European cities, based on a similarity of climate (broadly defined), although US locations are typically farther south than most European ones. For example, the latitude of Jackson, Mississippi is much further south than that of a supposed European correspondent, such as Italy or Spain. Jackson is as far south as Benghazi, Libya, which is six hundred miles south of Rome and 200 off the southernmost Italian location in Sicily. Further south, Miami, whose Latino heritage might induce some superficial inclination to align it with Spain, is in the middle of the Sahara desert. The biased logic of locating cities across regions and continents goes beyond mere operational cartographic logic. Maps, especially cognitive ones, are complex constructs. 'Implicitly and explicitly, they contain spatial relational data along with environmental attributes and individualized and socioculturally conditioned beliefs, values, and attitudes' (Golledge and Stimson, 1997: 236). Geography, as understood by ordinary people, is, in effect, experiential. It is, 'a complex domain that is learned about over the life span from a variety of eclectic sources and experiences, so reasoning about geographic entities can potentially be affected by perceptual (Huttenlocher et al., 1991), cognitive (Friedman and Brown, 2000b), and affective (Carbon and Leder, 2005; Kerkman et al., 2004) factors' (Friedman, 2009, p. 95). Proximity and location then are allocated according to a 'plausible reasoning logic' of designating spatial characteristics on the basis of non-spatial attributes, which often leads to cartographic judgments and biases.

As Golledge and Stimson emphasize (1997), the maps people carry in their minds are not precise mathematical models, complete with a precise coordinate system and exact location parameters, but cognitive models of socioculturally conditioned beliefs. These refer not to an abstract notion of space, but to specific places of which we have some cultural (in an anthropological sense) beliefs. In this we follow one of the tenets of humanistic and cultural geography, which defines space and place as two different concepts (Tuan, 1977; Curry, 2002; Cresswell, 2004). Space refers to an abstract concept, which contains specific places. Place could be defined as a 'site of specific meaning or intention' and it is 'the result of an ordering and categorization of our spatial experience' (Willis, 2007: 155) on the basis of a cultural system of beliefs. In this study we investigate how places are mentally mapped 
in cognitive spatial models that follow systems of beliefs derived from plausible reasoning that follows a procedural logic (Carbon et al., 2005). In this we follow Golledge and Stimson (1997: 163), who propose that cognitive spatial models include 'three components: declarative, which includes knowledge of objects and/or places with attached meanings and significances; relational or configurational, which includes ideas like proximity, sequence, and hierarchy; and procedural knowledge ('If... then...')'. As such, mental maps of places combine factual information about where a place is in terms of relative location from key landmarks (oceans or land mass contours) or cardinal points (e.g., North or South), with cultural attributes, such as 'who are the people who live there' and 'what regions they hail from' on the basis of a belief-based cultural methodology for connecting the two. Beliefs are based on pre-empiric assumptions that rest on claims of cultural similarities between people on the basis of the most apparent facet of their similarity: that of ethnic origin. As such, cognitive models that represent places display significant distortions and biases. Cultural biases are compounded by so called "categorical biases," which are caused by the attempt to align spatial realities with a given preconceived idea of spatial distribution in discrete categories (places) that are organized in the knower's mind hierarchically. Stevens and Coupe (1978) explored these processes in a direct way. They used classic geographical questions to reveal the hierarchical organization of spatial knowledge. For instance, they asked whether Reno or San Diego was further east; when most respondents answered Reno, it was because they judged that Nevada was east of California and thus made their decision on the basis of the states in which the cities were located (Stevens and Coupe, 1978: 248).

Categorical biases, by which places are attributed locations on the basis of their affiliation to a region, are just one type of spatial misattribution error. Locations can be inferred for cities or places on the basis of the inferences we make about the people who live there or about the socio-cultural characteristics of those areas, often culled from false memories assimilated through movies and media (Tversky, 1981). In other words, locations can be inferred not only from climate or regional categorization, but also by the logic of plausible reasoning, by similarities in cultural and social conditions that are supposed to be prevailing in a specific area. When imagining some places in terms of cultural similarities, they are being thought of as what we might call 'alterpodes.' Unlike antipodes, which are the exact geographic opposite of a location, an alterpode is a place that is thought as being both different and similar. An alterpode is perceived as a mirror image in another continental dimension. Alterpodes are dyadic realities. An alterpode corresponds to a matching place by virtue of ethno-cultural similarities. Alterpodes in the language of mental mapping correlate places invested with characteristics, including spatial ones (latitude, climate, distance) derived from judgments about the people who live there.

For example, if you believe that New York City is mainly populated by people of European Ancestry (Anglo, Irish, Jewish, Northern or East European), you might also situate it geographically at a similar latitude as other known European cities (London, Amsterdam, Berlin, etc.), which are or were the homes of the Western 
European, English, or German-Jewish populations. However, London, Berlin, or Paris are in fact much further north on the latitude scale, than New York City, which at 42 degrees $\mathrm{N}$ is almost on the same latitude as Naples, Italy.

Cultural critics, communication researchers, and scholars are increasingly interested in the connection between place perception and the mediated images that shape them (Kern, 2003). By extension, scholars have become interested in the potential mechanisms by which categorical or cultural biases distort cognitive representations of places. Such cognitive misrepresentations can be and often are induced by mass communication. Previous research has revealed several significant trends. Curry (1997) highlights the propensity of maps, cognitive or not, to assign various attributes to all individuals living in an area. The ecological fallacy of this assignment is particularly troubling when mapped because, as Curry argues, 'people tend to see maps as direct representations of reality in ways that tables and charts are not' (1997: 691).

Furthermore, in an increasingly connected world social interactions lose their exclusive connection with physical proximity (Giddens, 1990; Meyrowitz, 1983; Wellman, 2001) and through broadcasting media individuals can take part in public events diffused worldwide in real time (Dyan and Katz, 1992). Yet, this does not mean that people have a more accurate perception or understanding of the places that intersect their immediate or mediated experiences. In fact, as space has been 'domesticated', the boundaries between familiar and exotic, far and close, have been blurred (Kern, 2003). We often translate far away locations in our own terms, making them look more like our own world (Thompson, 1995). In a world dominated by media, the notion of place ceases to be coherent and fixed and it becomes open and dynamic (Castells, 1996). Constant access to media, traditional or digital, the adoption of wireless devices and social media and the production of user generated content deeply influence how individuals experience place. Mediated experiences transform our sense of presence and the perception of proximity and distance. A sense of mediated intimacy emerges (Thompson, 2008). Access to a continuous flow of information from institutional (media sites) and personal connections (friends, acquaintances, and social media connections) create an ambient awareness of faraway places.

More specifically, research in cognitive mapping, going back to Castells (1996), Golledge (1997), Kerkman et al. (2004) and more recently Kweon, Hwang, and Jo (2011) justifies the claim that place and space are culturally constructed. Kerkman et al. (2004) are particularly convincing in making the claim that cultural construction of space implies association of cultural stereotypes with spatial locations. Their groundbreaking study on misperception of North-South locations at a continental scale due to cultural stereotypes is particularly germane in this context. Following in their footsteps, we propose that perceptions of place and the mental maps we use to organize them are shaped by cultural perceptions modeled by core learning channels: personal experiences, social media interactions, knowledge gleaned from 
books and movies, experiences from fleeting interactions with mere acquaintances or lasting friendships with people who live abroad (globally, regardless of continent). The claim that cultural perceptions are shaped by mediated and personal learning is not new (Meyrowitz, 1983; Thompson, 1995). Carey, in his classic Communication as Culture (1988) in fact equates the two, seeing culture and cultural bias consubstantial with communication. Meyrowitz's medium theory (1983) makes a similar and even stronger claim, when it proposes that the contours of the world, social or otherwise, are symbiotically influenced by media content. According to it, specific types of content shape cultural perception of the world in specific ways. Orality supports certain mnemonic devices that favor linear thinking by which space and time are unidimensional and circular. Print media favors a Cartesian vision on space and time, in a two-dimensional, hierarchical, intrinsically ordered and open-ended, progressive universe. Electronic media explodes space and time, compressing the distance between space and time, as emphasized by Giddens (1990), and inviting a multi-perspective, relativistic image of the space, time, and the universe, physical and social, as a whole (Kern, 2003). With new media we have the possibility of new forms of perception and expression that need to be further explored.

In this study we push ahead the exploration of these issues seeing a variety of media (traditional and digital) intersecting with other forms of immediate communication to create new learning experiences with new cultural and spatial perceptive dimensions (Thompson, 1995). Building on Carey (1988), Giddens (1990), Kern (2003), Meyrowitz (1983), and Thompson (1995), we propose that if media effects shape our cultural biases generally, they would also affect cultural biases related to space. Spatial perception should be seen as the product of multiple sources of information. For operational clarity and consistency with traditional media effects literature interested in basic media experiences (Ball-Rokeach, 1985), and newer literature, which discusses perception of space (Carbon et al., 2005), we distinguish between immediate and mediated sources. Immediate sources include individual experiences such as travel and personal contact. Mediated experiences can be divided into: a) traditional sources (movies, books, etc.), b) on-demand, customizable, dynamic media (online maps, review or reference websites) and c) social interactive experiences offered by social media - social interactions with individuals we know through and interact with online.

Knowledge acquisition can also be divided into formal and informal experiences, the former referring mostly to educational experiences, while the latter to individualized exposure to a variety of resources, from books, to movies, to social media contacts.

Intersecting these three dimensions (immediate-mediated, formal-informal, traditional-digital media) can generate a comprehensive but rather cumbersome typology. Since our primary goal is to explore the role of mediated experience in shaping perception of place, our study cannot explore all quarters of this communication typology. We will focus mostly on traditional and digital media. In the latter case we 
distinguish between indirect exposure to faraway lands through the interactions with individuals we know through social media and more purposive searches for information about distant places using digital information sources, such as maps, reference sites, etc. The distinction between the two types of exposure is that while social media interactions shape our geographic knowledge indirectly and contextually, the latter type of digital media exposure is more direct and purposive. The distinction thus emphasizes modalities of influence.

In summary, our study focuses broadly on three separate domains of communicative processes: traditional media resources, digital communication knowledge resources, and social media engagement. This tripartite categorization responds to questions previously posited in the geo-spatial literature about our changing sense of place due to media effects on perception of space, as discussed above. For the purpose of this preliminary/pilot study these resources are operationalized as described below.

Traditional Media resources. These refer to the main mass mediated sources for learning about the world and about geography, such as books, movies, magazines, etc. These are typically consumed as stand-alone experiences. Both Friedman (2009) and Tversky (1981) suggest that information gleaned from the media can shape cartographic knowledge.

Digital Communication Knowledge Resources. In a networked world users on the move browse the web, search for information, and carry out personalized web searches according to their peculiar needs and locations (Gordon and De Souza e Silva 2011). Through a process of ,social annotation' citizens produce a large amount of information referring to different place experiences that can be shared with other users. Since our study is specifically focused on the changes brought about by the advent of digital and online communication media on geographic orientation and knowledge, particular attention needs to be paid to how much online maps, user generated content sites (TripAdvisor, YouTube etc.) or online news channels shape geographic knowledge. Digital online resources are in this context a focused concept, including online sources that are geographic in nature and highly interactive.

Social media engagement. Information gleaned from online sources is not limited to purposive, direct searching of information through online resources. A good deal of information about the world is transacted through social media (Facebook, Twitter, etc.). In this case, however, informing and learning is indirect and contextual. We learn about other places through inference, using as departing points messages or signals from our social media contact. Informing is a byproduct of sociability. We learn osmotically from the networks of interaction that we create based on choice and affinity (Castells et al., 2007). Following the 'networked individualism' perspective (Rainie and Wellman, 2012) each individual is conceived as a node within a network (ego-centered network), enabling/disabling social interactions according to personal experiences and current needs. In such a context, internet communication and, more specifically, social media platforms, enable not only the maintenance of long-distance 
ties but also create channels of indirect communication and learning about the places long distance ties originate from (Rainie and Wellman, 2012). Taking into account the number, the geographic distribution and the depth of social ties across these media is of paramount importance for understanding how geographic knowledge takes shape.

While we believe that these categories map conceptually onto the basic source of information that may affect spatial perception, we are aware that, in the contemporary media environment, digital and traditional media often overlap, while the boundaries between different media are blurring. we are also aware that the same media platform can enable different reception strategies among its audiences. Nevertheless, an analytic tradition in media research, informed especially by the media dependency system perspective, distinguishes between content genre effects (Ball-Rokeach, 1985). Consistent with literature discussing traditional media effects on space perception (Carbon et al.,2005; Golledge, 1997; Kern, 2003; Meyrowitz, 1983), we decided to use these discrete categories for analytical purposes. More important, although movies can be consumed online, we make a clear distinction between social media, as a specific genre, that communicates through posts and brief messages, and movies, as a type of long form artistic endeavor.

\section{HYPOTHESES AND RESEARCH QUESTIONS}

Our main proposition in this study is that when imagining the world outside our countries or continents, we rarely call on an objective cartographic method. Frequently, we use a categorical, social-cultural method of plausible reasoning, in which proximity is inflected by a sui-generis process of spatial reasoning, which is shaped by a number of communication and knowledge resources. Such resources can be mediated or unmediated. Of the mediated ones, we need to make a distinction between the more traditional channels (books, magazines, newspapers or movies consumed in a static/non-computer based environment) and the newer, online tools such as interactive maps, social media sites, including those dedicated to travel, media sharing sites, etc. For the purpose of this study, geo-spatial bias and the knowledge heuristics that may lead to these biases are explored via a mapping exercise. Respondents are asked to locate European cities in the US geographic space, and vice versa, keeping latitude and distance from most extreme continental points in the US and Europe constant. The basic assumption, as discussed above, is that mental maps at scale tend to be aligned according to a logic of cultural and ethnic similarity. To explore this assumption we posit that samples of European or American residents will generally make the same biased errors, in that they will try to geographically align US and European cities that seem to share assumed ethnic or cultural similarities. The exploration starts with questions about correct placing of United States or European Union cities on their correct latitude. This checks for accuracy and baseline geographic knowledge. 
After this preliminary exercise, the core questions are asked. Subjects are instructed to place a European or American city across the ocean in US or European space. The aim is to detect possible attempts to match geographic places with cultural locations. As suggested above, although about $80 \%$ of continental US is south of Rome, for cultural reasons, a general misconception might be that in fact most US locations are much further north than they are. Similarly, European locations will be perceived to be much further south than they should be, thereby aligning the two continents on latitude.

Since our theoretical model of plausible reasoning predicts that places will be aligned with cultural knowledge, we hypothesize that respondents will try to align US and European locations according to this logic. Southern or Northern US locations will be seen as being aligned with Southern or Northern European locations. Since the US is located farther south than most European countries, there will be a southerly bias for European cities and a northerly one for US cities. We thus hypothesize that:

$\mathrm{H} 1$ : European locations will be misplaced in the US space in a southerly direction

$\mathrm{H}$ 2: United States locations will be misplaced in the European space in a northerly direction

The literature did not explore in sufficient detail the possibility of differences between ethnic groups. Thus, our study will examine such differences as well:

RQ1: Are there any significant differences between European and US respondents in placing United States cities in Europe?

RQ2: Are there any significant differences between European and US respondents in placing European cities in the United States?

Finally, the sources of bias are explored taking into account the various knowledge resources that can influence place perception. Two final questions examine the impact of various resources and especially those that reside online.

RQ3: Do knowledge resources shape the biases, and if so, which ones?

RQ4: Of the online communication resources, which are more likely to shape the biases?

\section{METHODS}

A pilot survey of geographic locations was conducted among students attending either a leading, large size Italian or US Midwestern State University. Both universities were located in cities situated at similar geographic latitude (40 degrees North). A total of 301 college age respondents, 229 studying at a state university in the United States and 72 at an Italian University, were recruited in exchange for extra class credit (typically $1 \%$ of the semester grade) to fill out a 30 minute online survey. The students were selected as target group due to their relative educational, demographic, and technological use homogeneity. The samples are thus not 
representative of US or Italian populations. As pilot testing groups they are however indicative of certain comparable young learner, digitally adept populations. Surveys were administered in a computer lab under the supervision of the research coordinators. Students had no access to any outside materials and completed the survey without any interruption of the task. Although the students, especially those in the United States, included a variety of citizenships, for the purposes of this study we analyze and report the results only of the students that had United States or Italian citizenship ( $n=212)$. Out of 212 valid responses, 158 respondents $(74.5 \%)$ are United States citizens, 54 (25.5\%) are Italian citizens.

The study was conducted using the online survey platform Qualtrics. Most of the questions were in multiple choice format. The core geographic questions were presented as requests to place city locations on continental size image maps of Europe or the US. Both the US and European maps included areas not in Europe or US due to the fact that correct translation of locations demands some European cities to be placed in Canada and some US cities to be placed in Asia or North Africa. Maps depicted only terrain features and were devoid of any labels or city markers. As indicated below, some instructions were provided regarding west-east orientation. Both groups were asked to place cities in Europe and in US, equally, as detailed below.

\section{DEPENDENT VARIABLES}

The key dependent variable is error in placement of 14 cities (7 European, 7 US) in a different continental space. This error is interpreted as bias, in that we expect that errors go in specific directions, colored by cultural inferences based on plausible reasoning, as predicted by Hypotheses 1 and 2. Errors for US cities placed in Europe should go in a northerly direction, while those for European cities should go in a southerly one.

To capture such biases, participants were asked to place US cities in Europe and vice-versa. The participants were instructed to think about the location of Rome in its own original location. Then, they were asked to

'imagine that we moved Rome to a location on the map below depicting the US in the middle of North America\}. This place would be just as far south from the North Pole as it was in Europe. It should also be just as far west from the Atlantic coast, as it was east in Europe. In other words, if you think Rome is near the Atlantic coast, the selected location on the map below should also be near to the US Atlantic coast; if you think Rome is far from the Atlantic coast, the selected location on the map below should be as far from the US Atlantic coast. Click the map where ROME would be.'

The respondents were given a red line and a direction of reference for making east-west inferences. Each city (place) was placed on the map individually, on a separate map. The exercise did not aim to determine how the cities are related to each other. Rather, the goal was to measure average bias in placing individual cities (places) and then to use bias measurement to obtain an approximate US / European bias measurement. 
Cities were chosen at a variety of distances and in a variety of locations relative to the respondent places of domicile to minimize bias due to proximity to one's own present location.

Operationally, each city location marked by the respondent on the map was recorded in the dataset as a pair of coordinates. For each respondent a North-South Error average error was calculated for each continent and for each mapping exercise, subtracting the average value for real locations from the average value of the locations indicated by the respondents. West-East biases were not used in this study. For city locations we used points (centroids) obtained from the National Geographic Atlas. In effect, for each respondent we obtained two average values: one for N-S error/bias for placing all 7 US cities in Europe, and one for all 7 European cities in the US.

The average biases for placing cities are presented in Figures 1-2. On each map the origin marker represents the location of the city if latitude and distance from the coast are kept constant. The lighter (pink) arrow points to the average location of the city for all the Italian participants. The arrow, thus, represents the mean Italian bias (error). The darker arrow (blue) does the same for U.S. participants. As expected, a strong and consistent northern bias can be seen in the placement of U.S. cities in Europe (Figure 2) and a southern bias in the placement of European cities in the U.S. (Figure 1). Biases are quite similar, with some differences, which will be tested for significance below.

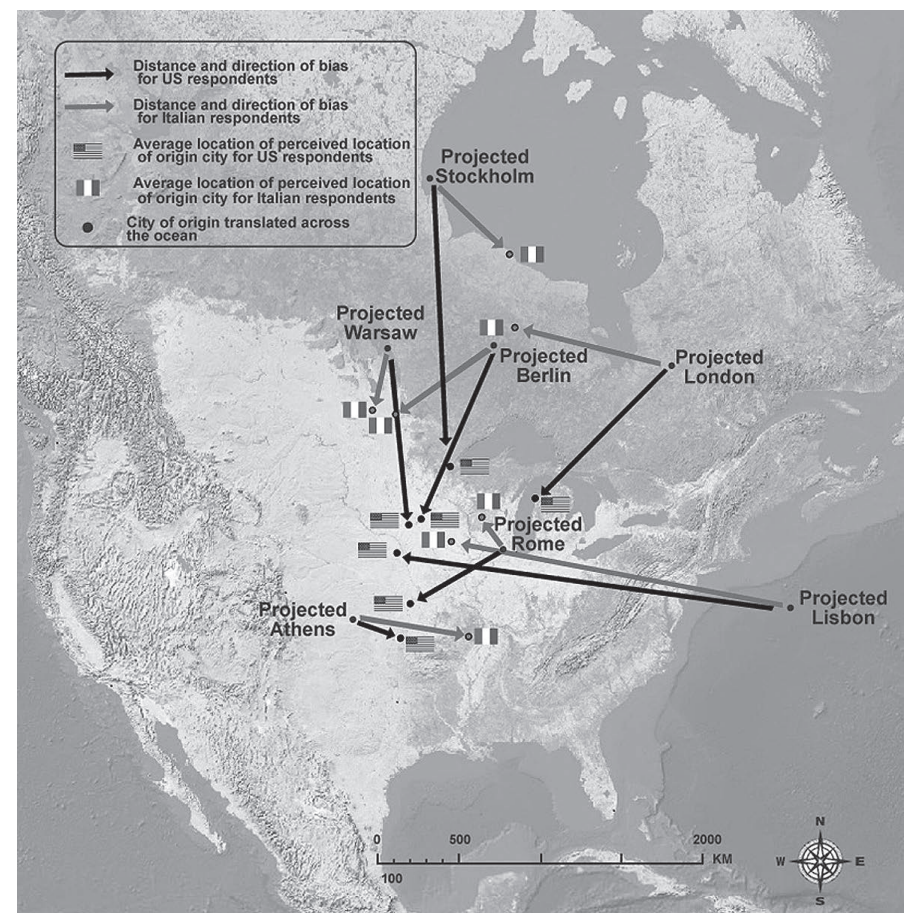

Figure 1. Error in projected placement of European cities in the U.S. Both US and Italian respondents place locations further south than they should be. Lisbon, which is less recognized even in Europe, presents a Westerly bias. 


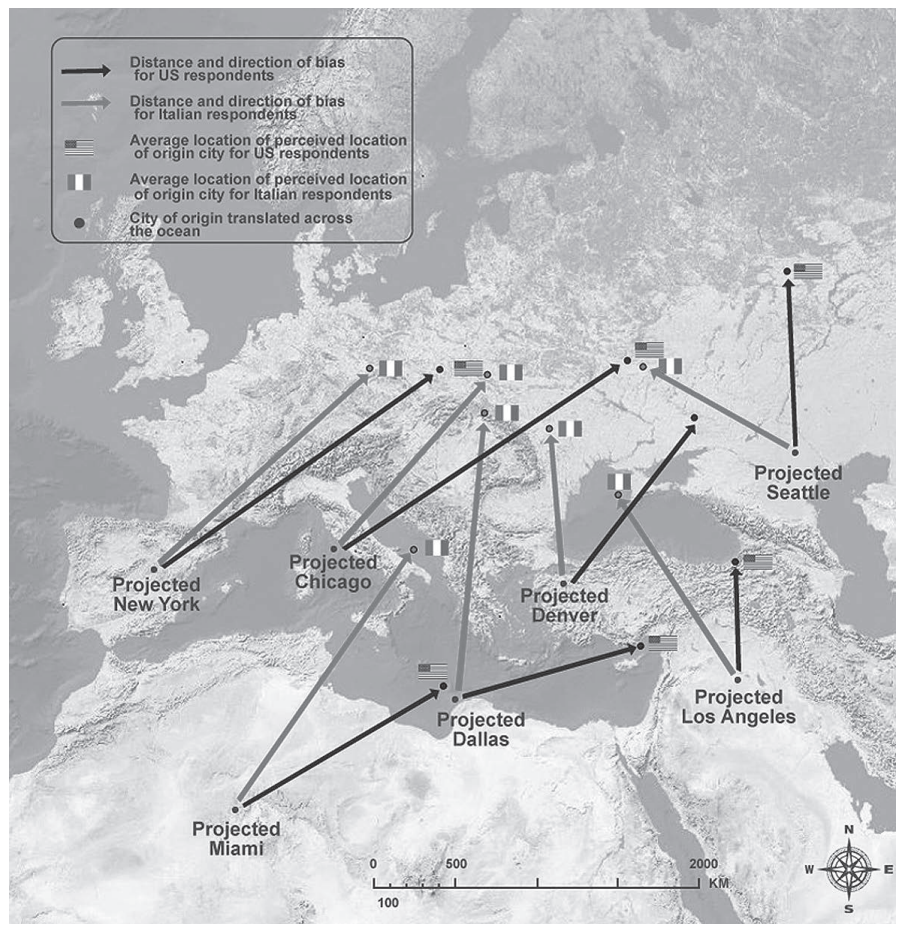

Figure 2. Error in projected placement of U.S. cities in Europe. Both Italian and US students place most US locations much farther north then where they should be. New York is in Germany, Chicago in Poland, and Miami in Italy/Greece.

\section{INDEPENDENT VARIABLES}

Placement biases can be the product of a number of factors. Some, as discussed above, might originate in the media, some in contextual and indirect learning about locations from interactions with social media contacts, while others arise from individual educational or perceptual experiences. At the same time, in detecting the sources of bias one needs to control for the different levels of actual geographic knowledge, from the simplest (meaning of north and south or east and west) to the more complex, including actual knowledge of where various cities are in their own continental spaces.

To control for actual geographic knowledge, participants were asked to place the cities in their expected geographic space: United States cities mapped onto a topographical representation of the U.S. situated in the middle of North America, European cities onto a topographical representation of Europe. This captures accuracy of geographic knowledge relevant for this exercise. Deviations from placement in the expected places were used as controls in the multiple regressions reported. Figures 3 and 4 depict the raw data. Average errors in terms of actual placement of the cities in their correct locations are represented as before, as arrows. 


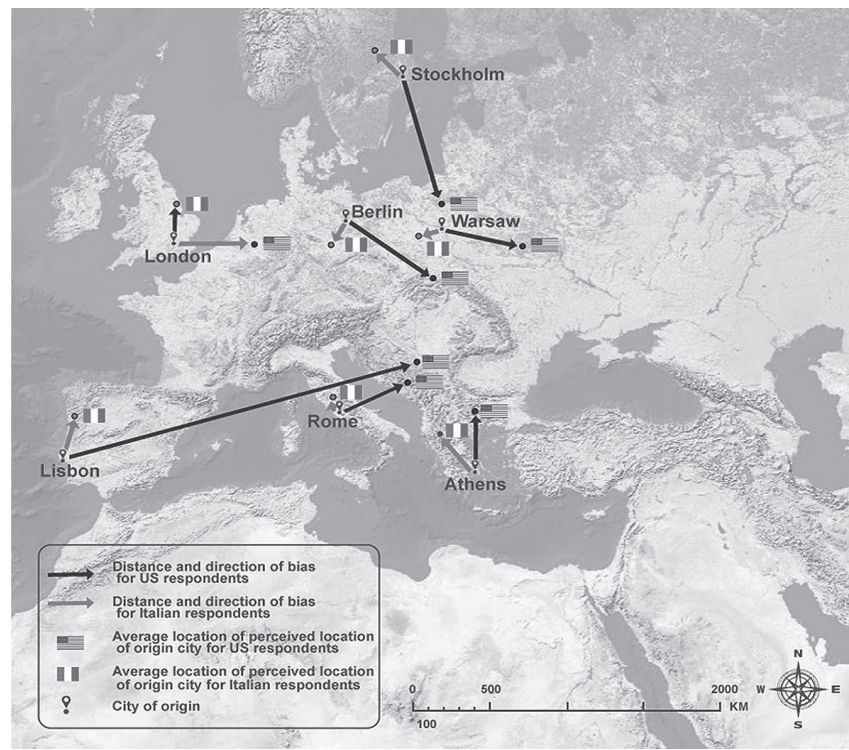

Figure 3. Accuracy of geographic knowledge when locating European cities in Europe. Light lines - Italian respondents. Dark lines - US respondents.

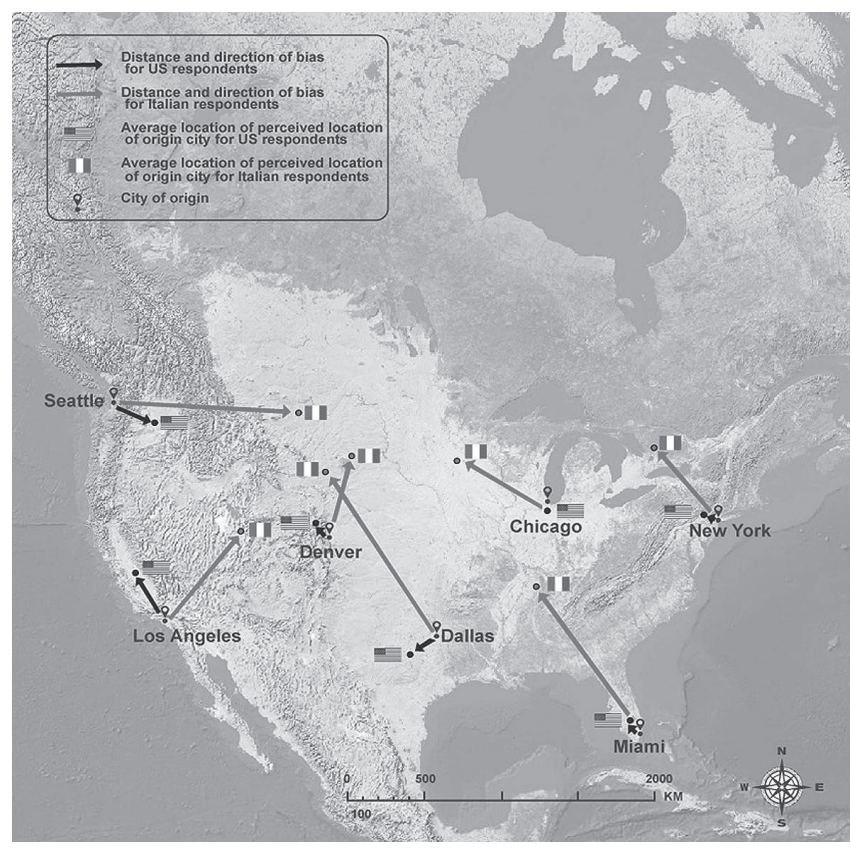

Figure 4. Accuracy of geographic knowledge when locating US cities in US. Light lines - Italian respondents. Dark lines - US respondents.. 
Overall, errors of location for cities in one's own continental space are lower. However, there is a clear bias in placing locations in continental spaces that are not one's own. Italians placed most US cities further up north than where they should be, and US students placed them further west. U.S. participants also tended to push southern European cities further north and northern European cities further south than where they should be.

The second set of independent variables in this study refers to the sources that might shape geographic knowledge. As already justified in the literature review and detailed in the appendix (http://alterpode.com/), which provide the wording and the summary statistics for the items, we looked at three groups of factors as potential explanatory or control variables.

\section{Traditional media}

For each city the questionnaire assessed to what degree mental images of city locations were influenced by a number of traditional communication (books, movies, magazines, education etc.). Questions were asked in the format 'How much of these sources contributed to your image?' and the metric was 'a lot, some, little, not at all.'

\section{Broad Internet communication and knowledge resources}

A distinct category of variables explored the degree to which respondents rely on digital/online/social media to learn about geography. Questions referred to online maps, travel sites, reference sites, etc. The questions were asked in the format: 'How frequently have you used \{source: online maps, reference sites, etc.\} to \{locate places, learn about locations, or contributed/used content to travel reference sites\} about \{locations not in your own country\}' (see http://alterpode.com/).

\section{Amount of social media engagement:}

Another set of questions explored interaction via social media with people living in countries where the cities included in the study are located. Questions addressed frequency of communication with close friends via social media, as well as magnitude of constant contact with individuals who live in Europe or US. These questions are different from the ones mentioned above, referring to social contact, not to specific information queries. The goal is to measure amount of social contact and to use this as a proxy for contextual learning about various places in the world. For details see appendix at http://alterpode.com/.

\section{RESULTS}

Single sample t-tests for significance of departure from 0 (no error) were used to detect biases in misplacing European and U.S. cities when projecting them across the Atlantic. Appropriate procedures for accounting for equality of variance were used. The tests provide answers to the first two hypotheses: H1: European locations will be misplaced in the US space in a southerly direction; H2: United States locations will be misplaced in the European space in a northerly direction. 
The average error of latitude location for all European cities placed in the United States and for all U.S. cities placed in the European Union space were used as the test variables. The results indicate that in both cases the null hypothesis should be rejected. The average bias for United States cities placed in Europe was positive, showing a northerly bias, $(M=149.18)$ and the $t$-value for difference from zero (no bias) is highly significant $(t(211)=19.35, p<.01)$. The Cohen effect size is very high $\mathrm{d}=1.31$ and the actual power is .96. As expected, the average bias for European cities placed in the United States was negative, indicating a southerly bias ( $M=-75.17)$ and the $t$-value for difference from zero (no bias) is also highly significant $(t(211)=-9.85$, $p<.01$ ). The Cohen effect size value is moderate-high $d=.7$ the actual power .95 .

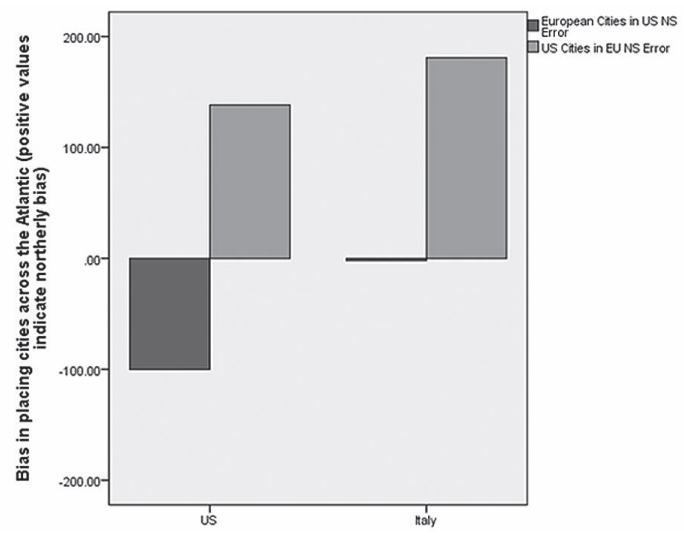

Figure 5. Bias in mapping cities from one continent to another by Italian and US students (x axis represents citizenship of respondents). Both Italian and US students show a strong bias when placing US cities in Europe. US students also place European farther south than they should be, while the Italian bias is minuscule.

With respect to RQ1 and RQ2, which ask if there are significant differences between European (Italian) and United States respondents in placing United States cities in Europe or European cities in the United States, t-tests for independent samples indicate that there are indeed significant differences between the two populations in their placements of cities from one continent into another. Specifically, although both samples tended to place U.S. cities in Europe further north than where they should be, the Italians did so to a greater extent than the U.S. participants. The t-test indicates $(t(210)=-2.40, p<.05)$ that the Italian sample mean difference from average real location $(M=180.80, S D=118.34)$ is significantly different from the United States sample $(M=138.75, S D=110.14)$. The Cohen effect size value is moderate-low, $d=.4$ and the observed power is .95. The t-test for placing European cities in the United States, indicates $(\mathrm{t}(210)=-4.91, \mathrm{p}<.01)$ that Italians $(\mathrm{M}=-1.93, \mathrm{SD}=137.55)$ placed locations quite accurately, compared to the United States respondents, who had a clear southerly bias $(M=-100.20, S D=87.93)$. The Cohen effect size is very high $\mathrm{d}=.85$ and the observed power is .95 . A representation of the data on bias by group can be seen in Figure 5. 
Finally, to determine the impact of knowledge resources and social media connections on location bias (RQ3 and RQ4) we regressed positive (northerly) error for United States cities placed in an European context and negative (southerly error) of European cities placed in a United States context on the knowledge resource (see Appendix, III, Table 1 at http://alterpode.com/) and control variables. The procedure truncates the dependent variables to include only values that drift north for United States cities placed in Europe and only those that drift south for European cities placed in Europe. Truncation was justified by the directionality of the bias detected upon testing Hypotheses 1 and 2. At the same time, truncation would provide true estimates for bias. When the regression coefficients are positive and significant, they indicate that the independent variables contribute to bias. If they are negative and significant they reduce the bias. If the dependent variables were not truncated, negative values for regression coefficients would indicate that they contribute to a outherly bias, not to a more accurate representation of geography.

The SPSS regression model selection procedure with forward elimination was used. The procedure included trimming outlier cases and replacing missing values with series means. In addition, when a categorical variable was found non-significant, each level was tested separately via a dummy variable procedure to detect discrete effects at the category level. Two final models were obtained, one for predicting bias in placing European cities in the United States and one for placing United States cities in Europe.

The results for analyzing the positive (northerly) bias associated with placing U. S. cities in the European space indicate that knowing about U.S. cities from movies $(B=33.12, p<.05)$ contributes to this bias. Using or not using online maps also had an effect on bias. Although, overall, the map use variable did not provide either a positive or a negative bias, follow up tests of each level of the variable indicated that those who do not use online maps to explore places outside their home country placed US cities in Europe with more accuracy $(B=-172.201, p<.01)$. However, this should be interpreted with caution, since as mentioned those who do use maps were no more or less likely to make errors. In other words, while map usage is not detrimental to geographic knowledge, those that do not use online resources make on average better geographic guesses. Finally, those who have never contacted people who live abroad via online tools to learn about foreign countries were more likely to make northerly errors $(B=-32.82, p<.05)$. In this context, social disconnection is associated with bias. The model R2 $=.15$. These effects are net of the effect actual geographic knowledge has on misplacing cities, since misplacing of U.S. cities to the north when originally mapping them onto the United States was controlled for and was found to be significant $(B=0.53, p<.01)$.

When placing European cities in the US, all respondents, regardless of ethnicity, made greater errors, again, when they had originally misplaced cities in their own continents, mostly in a southerly direction $(B=.19, p<.05)$. At the same time, those that relied more on internet communication to ask for geographic information about foreign countries were less likely to display a southerly bias when positioning 
European Cities in the United States $(B=-123.56, p<.05)$. Similarly, but only marginally significant, those that commented on current affairs through blogs and user generated content sites were also less likely to make misattribution errors $(B=-28.76$, $\mathrm{p}=.07)$. The model $\mathrm{R} 2=.08$.

\section{DISCUSSION}

The present study aimed to determine to what degree geographic biases are present in European (Italian) and US college age students' representation of space at a continental scale, the direction of these biases, and to what degree such biases reflect biases due to various knowledge experiences and channels. The results indicate that biases are indeed present and in the expected direction. When asked to place U.S. cities in a location at the same latitude in Europe, both Italian and U.S. students tended to place the cities much further to the North than where they should be, suggesting an assumption of cultural similarity, as suggested by the previous literature (Friedman, 2009). In other words, respondents made the 'plausible reasoning' argument that since United States and European cities are populated by people of largely the same heritage, they should share the same latitudinal location, pushing the U.S. cities up north, toward an assumed space of 'origins.' Thus, our findings seem consistent with previous literature (Friedman, 2009), which suggests that judgments about cultural similarity are transferred to geographic reasoning. Similarly, when placing European cities in the United States, the U.S. students, tended to place the European cities much further south than they should be. This reflects an attempt to 'normalize' the European cities to a 'standard' Euro-Atlantic space. Interestingly enough, the Italian students were relatively more accurate in their perceptions, their biases manifesting more intensely when translating U.S. cities in a European space. The reason for this error asymmetry remains to be investigated. A possible answer could be the greater emphasis on specific, factual knowledge in historical and geographical education in Italy.

The more interesting findings of our study relate, however, to the potential sources for such biases. An obvious one is, of course, basic knowledge of geography. Biases in placing both sets of cities across the Atlantic were related to ability to correctly position United States or European cities in their own geographic frames of reference. However, knowledge sources are also responsible for biased views of geography and their effects are independent of geographic knowledge.

Regarding misplacing U.S. cities in the European space, movies are an important source of such bias, a finding that suggests that the fictional world of cinema, which tends to equate American and European spaces liberally, might have a real life effect. Stereotypical images of U.S. colleges as replicas of English medieval university towns, or of Los Angeles as an Ibero-Mediterranean city can be an impetus for thinking that U.S. cities are located about the same place where some of their imaginary 'peers' would be. 
More interestingly, online map use does not seem to help alleviate biases in placing U.S. cities in Europe. However, connections to people living abroad were correlated with lower biases, providing some support for the impact of osmotic learning (Castells et al., 2007) on cognitive mapping. Why map use does not reduce bias is to be further investigated, especially in view of the fact that we detected a bias reduction for the small subsample of those that do not use online maps. A hypothesis could be that online maps (e.g. GPS devices and mobile maps apps) propose an extremely personalized, automated and often narrow cartographic spatial representation that does not support a comparative and contextual spatial knowledge.

For placing European cities in the United States, we again found that in addition to basic knowledge of geography, biases are mitigated by interacting with other people online to learn about foreign countries or by being actively engaged with social media, by commenting or contributing to user generated sites (blogs, media sharing, news sites, etc.). This means that biased perception of latitudinal location of major United States and European cities seems to be mitigated by asking online peers abroad for help in figuring out where places are in foreign lands. The portable 'experts' selected from one's online 'bubble of sociability' seems to be quite useful in correcting images about latitudinal location of cities. On the other hand, images of cities, especially those in the United States, portrayed by movies tend to bias location of United States cities on latitude. Overall, the findings for Internet connectedness in both settings suggest a positive role for using the Internet, specifically in an interactive manner, in order to reduce biases in mapping.

\section{CONCLUSIONS AND FURTHER RESEARCH DIRECTIONS}

Given the explosion of location aware media, Internet resources related to travel and geography, social media, online maps, and the rapid diffusion of mobile devices, more attention should be paid to how these media impact cartographic knowledge and our perceptions of space and place. The present study expands a research line on the impact of traditional media on cartographic knowledge (Friedman, 2009; Kerkman et al., 2004; Tversky, 1981) that emphasizes the role of cultural biases on spatial perception. In this respect, we build on Kerkman et al. (2004), who highlighted the role of cultural and social attitudes on spatial perception. As media affect cultural attitudes, we expand the discussion about cultural effect by introducing the role of mediated experiences, traditional and digital, on spatial perception. Our study also continues and expands previous work exploring the impact of digital media and social networks sites on spatial knowledge (Castells et al., 2007; Gordon and De Souza e Silvia, 2011; Kweon, Hwang and Jo, 2011). The data presented here make tangible the insights expressed by Carey (1988), Meyrowitz (1983), or Kern (2003) that media content shapes cultural patterns of perception and spatial organization. Media consumption is proposed in our study as a heuristic process of world "discovery" in which the contour of what is known is not dictated only by physical but also by the cultural geography of the mind. Some of the results produced by our 
work make even more visible what Carey as early as 1988 suggested, namely that communication processes are in fact cultural processes and that in communication we build cultural patterns that may affect even fundamental categories of human understanding, such as space. Cultural patterns related to space are seen to emerge in a process of plausible reasoning, captured here through our mapping exercises followed by exploration of spatial perceptions.

Our study provides only preliminary findings, which should be continued with additional research to further examine media practices and the social-psychological mechanisms that encode spatial knowledge. Understanding what communication channels are most effective in reducing bias as well as cultivating accurate knowledge and understanding of other places could be advantageous as the world moves toward a more globalized and interdependent society. While, contact with other people seems to be important in shaping knowledge of geography, a more complex index needs to be developed and validated that could measure synthetically the impact of social media connections on cartographic knowledge. Such research could enrich our understanding of how a global, connected world reshapes the way in which people perceive each other through the lens of geography.

This study is limited by the focused nature of the samples. The samples are not representative and our conclusions are naturally limited to those of a pilot study. Drawing samples from various European and US cities, which is also part of our research program, could help better understand and validate the biases detected in this study. Moreover, in the context of a growingly globalized society, broader understanding of such dynamics could also benefit from investigating the geographic perception of non Euro-Atlantic population. We intend to deploy a multicultural/ transcontinental study using a widely available, open source, creative commons toolkit, which could expand the scope of our study tremendously and make it truly representative. A web platform has been prepared at http://anonymizedforeview. The site allows real time data collection of information and interaction with participants from China, Europe, US, and Africa.

We hope that this line of research will further contribute to a deeper understanding of the role of cultural and communicative factors in shaping our understanding of global geography.

\section{REFERENCES}

Ball-Rokeach SJ (1985) The origins of individual media system dependency: A sociological framework. Communication Research 12: 485-510.

Carbon CC and Leder H (2005) The Wall inside the Brain: Overestimation of distances crossing the former iron curtain. Psychonomic Bulletin \& Review 12: 746-750.

Carey J (1988) Communication as culture. Boston, MA: Unwin Hyman.

Castells M, Fernández-Ardèvol M, Linchuan Qiu J and Sey A (2007) Mobile communication and society. A global perspective. Cambridge, MA: MIT Press. 
Castells M (1996) The rise of the network society. Oxford: Blackwell.

Cresswell T (2004) Place: A short introduction. Chichester: Wiley-Blackwell.

Curry MR (1997) The digital individual and the private realm. Annals of the Association of American Geographers 87: 681-699

Curry M (2002) Discursive displacement and the seminal ambiguity of Space and Place. In: Leah L and Livingstone S (eds) The handbook of New Media: Social Shaping and Consequences of ICT. London: Sage, pp. 502-517.

Dayan D and Katz E (1992) Media events: The live broadcasting of history. Cambridge, MA: Harvard University Press.

Friedman A and Brown NR (2000a) Reasoning about geography. Journal of Experimental Psychology 129: 193-219.

Friedman A and Brown NR (2000b) Updating geographical knowledge: Principles of coherence and inertia. Journal of Experimental Psychology: Learning, Memory and Cognition 26: 900-914.

Friedman A (2009) The Role of Categories and Spatial Cuing in Global-Scale Location Estimates. Journal of Experimental Psychology: Learning, Memory, and Cognition 35(1): 94-112.

Giddens A (1990) The consequences of modernity. Cambridge: Polity.

Golledge RG and Stimson RJ (1997) Spatial Behavior: A Geographic Perspective. New York: Guilford.

Gordon E and de Souza e Silva A (2011) Net locality: Why location matters in a networked world. Wiley-Blackwell.

Huttenlocher J, Hedges LV and Duncan S (1991) Categories and particulars: Prototype effects in estimating spatial location. Psychological Review 9: 352-376.

Kerkman DD, Stea D, Norris K and Rice JL (2004) Social attitudes predict biases in geographic knowledge. Professional Geographer 56: 258-269.

Kern S. (2003) The Culture of Time and Space, 1880-1918: (2nd edition). Cambridge, MA: Harvard University Press.

Kweon SH, Hwang KH and Jo DH (2011) Time and Space Perception on Media Platforms. In: Proceedings of the Media Ecology Association, 12th Annual Convention, Edmonton, Canada, 23-26 June 2011, pp. 25-48.

Meyrowitz J (1983) No sense of place. New York: Oxford University Press.

Rainie L and Wellman B (2012) Networked. The new social operating system. Cambridge, MA: MIT Press.

Thompson JB (1995) The media and modernity. A social theory of the media. Cambridge: Polity.

Thompson C (2008) Brave new world of digital intimacy. The New York Times, 7 September. Tuan YF (1977) Space and Place: The Perspective of Experience. Minneapolis, MN: University of Minnesota Press.

Tversky B (1981) Distortions in memory for maps. Cognitive Psychology 13: 407-433.

Willis K (2007) Sensing Place: Mobile and Wireless Technologies and Urban Space. In: Frers L and Meier L (eds) Encountering Urban Places. Visual and Material Performances in the City. Hampshire: Ashgate, pp. 155-169. 
112 I MENTAL MAPPING

\section{NOTES}

1. A previous version of this paper was presented under the title "Alterpode: Where we think things are and what influences those beliefs" at the November 20-24, 2013 National Convention of the National Communication Association in Washington, DC 